Rakenteiden Mekaniikka

Vol. 50, Nro 1, 2017, s. 17-24

http://rakenteidenmekaniikka.journal.fi/index

https:/doi.org/10.23998/rm.63420

CKirjoittajat 2017.

Vapaasti saatavilla CC BY-SA 4.0 lisensoitu.

\title{
Suurten siirtymien teorian opetuksesta
}

Eero-Matti Salonen

Tiivistelmä. Artikkelissa tarkastellaan eräitä suurten siirtymien teorian opetukseen liittyviä yksityiskohtia. Erityisesti korostetaan kontinuumin alku- ja nykytilojen eroa: alkutilaa esittäviin kuviin ei tule liittää näkyviin mitään voimasuureita. Massavoiman intensiteetin ja pseudotraktion sisältöä pyritään havainnollistamaan kahden yksinkertaisen esimerkkitapauksen avulla.

Avainsanat: suurten siirtymien teoria, alku- ja nykytila, mekaniikan opetus

Vastaanotettu 9.1.2017. Hyväksytty 10.4.2017. Julkaistu verkossa 19.5.2017.

\section{Johdanto}

Valtaosa rakenteiden mekaniikan ja lujuusopin probleemeista voidaan käsitellä käytännössä riittävällä tarkkuudella pienten siirtymien teorian avulla. On kuitenkin tapauksia, joissa tarkastelu täytyy suorittaa suurten siirtymien teorian avulla, jotta saavutettaisiin riittävän realistisia tuloksia. Tästä ehkä yksinkertaisin esimerkki on nurjahdus, jossa sauvan tasapainoyhtälöitä muodostettaessa ei riitä käsittely pelkästään sauvan nurjahtamattoman alkutilan suhteen. Ainakin jonkinasteinen suurten siirtymien teorian mukainen formulaatio on otettava silloin käyttöön.

Opetuksessa suurten siirtymien teoriaa edeltänee normaalisti pienten siirtymien teoria. Pienten siirtymien teoriassa kappaleen alku- ja nykytilan välinen ero jää helposti piiloon. Askel suurten siirtymien käsittelyyn vaatii tämän eron voimakasta korostamista ja aihe ei ole välttämättä aivan helposti omaksuttavissa. Artikkelissa esitetään muutamia opetukseen liittyviä painotuksia, jotka voivat helpottaa aihepiirin sisäistämistä.

\section{Merkinnöistä}

Kontinuumimekaniikan merkinnät vaihtelevat melko paljon eri oppikirjojen välillä. Tässä sovelletaan lähinnä lähteen [1] merkintöjä kuitenkin ilman indeksejä (kuva 1). Riippuvuudet 


$$
x=x(X, Y, Z, t), \quad y=y(X, Y, Z, t), \quad z=z(X, Y, Z, t)
$$

määrittävät kappaleen aseman mielivaltaisella ajan hetkellä $t$. Tällöin ainepisteellä, jolla on alkutilassa karteesiset suorakulmaiset koordinaattiarvot $X, Y, Z$, on nykytilassa hetkellä $t$ karteesiset suorakulmaiset koordinaattiarvot $x, y, z$. Edellisiä koordinaatteja voidaan nimittää materiaali- tai ainekoordinaateiksi ja jälkimmäisiä spatiaalikoordinaateiksi. Tässä käyttöön otetut merkinnät eivät ole välttämättä sen suositeltavampia kuin monet muut kirjallisuudessa esitetyt, mutta toimivat kuitenkin jatkossa esityksen pohjana.

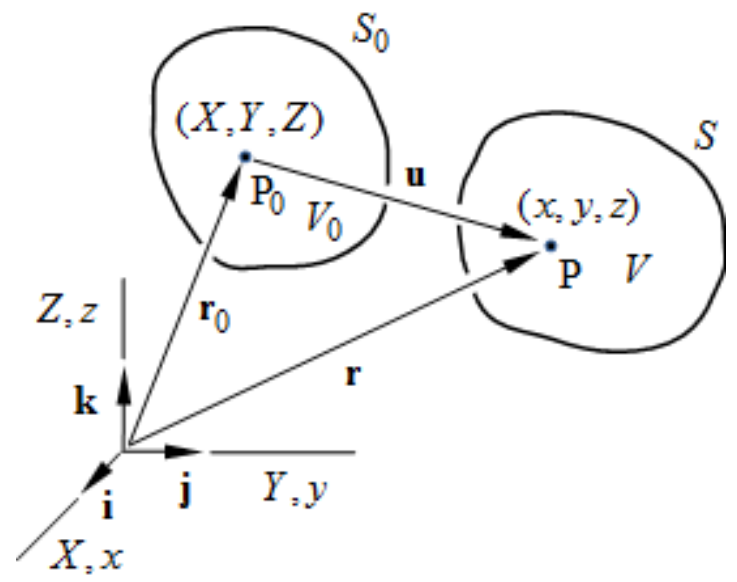

Kuva 1. Kontinuumikappale alku- ja nykytilassa.

Merkintää 0 käytetään tässä viittaamaan tarvittaessa alkutilaan. Merkinnän sijainti indeksinä tietyn tunnuksen yhteydessä voi vaihdella. Kappaleen alkutilan ja nykytilan varaamia alueita ja niiden reunoja merkitään vastaavasti tunnuksilla $V_{0}, V$ ja $S_{0}, S$. Siirtymävektorin u suorakulmaiset karteesiset komponentit voidaan myös kirjata kaavojen (1) tyyliin muotoon

$$
u=u(X, Y, Z, t), \quad v=v(X, Y, Z, t), \quad w=w(X, Y, Z, t) .
$$

Matemaattishenkisessä kirjallisuudessa pyritään tekemään tarkka merkinnällinen ero funktion ja sen arvon välillä. Tätä korostettaessa esimerkiksi riippuvuudet (2) voitaisiin kirjoittaa vaikka seuraavasti:

$$
u=\alpha(X, Y, Z, t), \quad v=\beta(X, Y, Z, t), \quad w=\gamma(X, Y, Z, t) .
$$

Kun sitten jatkossa joudutaan muodostamaan lukuisia derivaattoja, syntyy hämäävä tunnuksien sekamelska tai kuten lähteessä [2, s. 39] todetaan: "it is found that this practice can lead to a confusing prolification of symbols." On ehdottomasti parempi käytäntö tulkita funktioesityksiä kuten on selostettu arvovaltaisessa lähteessä [1, s. 139]: "and will write the motion equation $\mathbf{x}=\mathbf{x}(\mathbf{X}, t)$ without any subscript to identify the reference configuration. In the motion equation the symbol $\mathbf{x}$ appears twice with two different meanings. On the right-hand side $\mathbf{x}$ represent the function whose arguments are $\mathbf{X}$ and $t$, while on the left-hand side it represents the value of the function, i.e., the point 
x." Selostettu aihe ei tietenkään liity pelkästään suurten siirtymien teoriaan, vaan yleensäkin kontinuumimekaniikkaan.

\section{Voimien esityksestä}

Kiinteän aineen mekaniikan tavanomainen matemaattinen käsittely perustuu ns. Lagrangen esitystapaan, jossa suureita tarkastellaan muodossa $u=u(X, Y, Z, t)$ jne. eli riippumattomina paikkakoordinaatteina ovat alkutilan ainekoordinaatit $X, Y, Z$. Täten siis matemaattinen käsittely viedään kappaleen alkutilaan alueeseen $V_{0}$ ja sen reunaan $S_{0}$. Koska kappaleeseen vaikuttavat voimat liittyvät kuitenkin kappaleen nykytilaan ja alueeseen $V$ ja sen reunaan $S$, tuntuu luonnolliselta ajatella nykytilaa tarkastelun pääkohteena. Näin tietenkin on fysikaalisesti, mutta ei tässä matemaattisesti: fysiikka tapahtuu nykytilassa, mutta matematiikka alkutilassa. Tämän seikan jatkuva korostaminen helpottaa suurten siirtymien teorian omaksumista.

Särön muodostuminen on eräs esimerkkitapaus, jossa alku- ja nykytilan ero tulee selvästi esille. Fyysinen auennut särö nykytilassa ilmenee alkutilassa matemaattisesti pintana, jonka läpi kuljettaessa funktio $\mathbf{u}=\mathbf{u}(X, Y, Z, t)$ saa arvoonsa hypyn. Tässä esimerkissä käyttäytymisero tulee siis esille jo ilman vaatimusta suurista siirtymistä.

Alkutilassa ei normaalisti otaksuta vaikuttavan mitään voimia. Näin otaksutaan tässäkin jatkossa. (On tietenkin tapauksia, joissa alkutilaa ei voida määritellä mielekkäästi ilman alkujännitysten mukanaoloa. Tyypillisiä tapauksia ovat maa- ja kalliomekaniikan tietyt sovellukset.) Nykytilan voimien ja jännitysten katsotaan siis liittyvän kappaleen saamaan siirtymään $\mathbf{u}=\mathbf{u}(X, Y, Z, t)$.

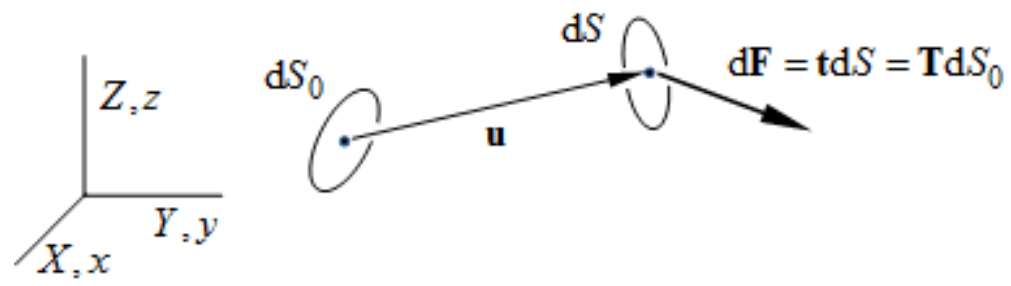

Kuva 2. Kaksi tapaa esittää pinta-alkioon $\mathrm{d} S$ vaikuttava voima-alkio dF .

Kuvassa 2 tarkastellaan alkutilan pinta-alkiota $\mathrm{d} S_{0}$, joka on siirtynyt nykytilan pinta-alkioksi $\mathrm{d} S$. Tähän liittyvää jännitysvektoria eli traktiota merkitään tunnuksella $\mathbf{t}$. Täten alkioon vaikuttaa pintavoima $\mathrm{d} \mathbf{F}=\mathbf{t} \mathrm{d} S$ ja itse kappaleeseen (sen nykytilassa) vaikuttavien pintavoimien resultantti on siis

$$
\mathbf{F}=\int_{S} \mathbf{t} \mathrm{d} S
$$

Kun merkitään kuvan 2 mukaisesti vaihtoehtoisesti $\mathrm{d} \mathbf{F}=\mathbf{T} \mathrm{d} S_{0}$, saadaan kappaleeseen (sen nykytilassa) vaikuttavien pintavoimien resultantiksi vaihtoehtoisesti

$$
\mathbf{F}=\int_{S_{0}} \mathbf{T} \mathrm{d} S_{0}
$$


Tämä jälkimmäinen on haluttu muoto, koska se liittyy alkutilan geometriaan ja matematiikkaan. Mutta vaikka integraali on otettu alkutilan pinnan yli, mitään pintavoimia ei siis tietenkään vaikuta alkutilan kappaleeseen. Näin kehiteltyä "keinotekoista" traktiota $\mathbf{T}$ nimitetään pseudotraktioksi tai nimellistraktioksi, koska

$$
\mathbf{T}=\frac{\mathrm{d} S}{\mathrm{~d} S_{0}} \mathbf{t}
$$

ja kyseessä ei siis ole tavanomainen jännitys (Cauchyn jännitys), joka saadaan jakamalla vaikuttava voima-alkio vastaavalla pinta-alkiolla. Määritelmän (6) taka-ajatus on ilmeinen: näin saadaan pintavoimien resultantti ilmaistua yksinkertaisesti alkutilan geometrian avulla.
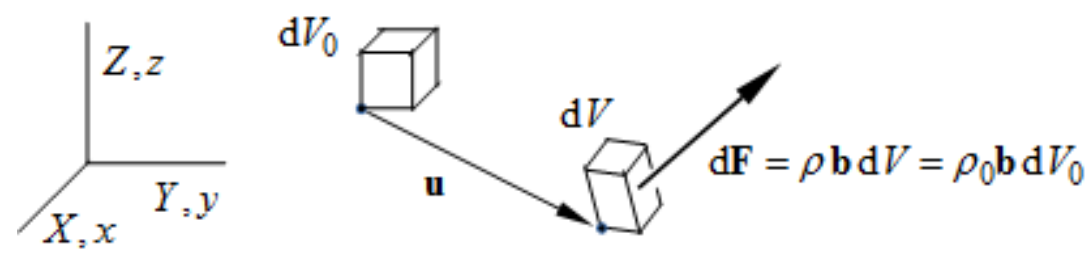

Kuva 3. Kaksi tapaa esittää tilavuusalkioon $\mathrm{d} V$ vaikuttava voima-alkio $\mathrm{d} \mathbf{F}$.

Kuvassa 3 tarkastellaan alkutilan tilavuusalkiota $\mathrm{d} V_{0}$, joka on siirtynyt nykytilan tilavuusalkioksi $\mathrm{d} V$. Kappaleeseen (sen nykytilassa) vaikuttavien massavoimien intensiteettiä (voima/per massa) merkitään tässä tunnuksella b. Tilavuusalkion massa $\mathrm{d} m=\rho \mathrm{d} V$, jossa $\rho$ on tiheys kyseisessä pisteessä. Täten tilavuusalkioon $\mathrm{d} V$ vaikuttaa massavoima $\mathrm{d} \mathbf{F}=\rho \mathbf{b d} V$ ja kappaleeseen vaikuttavien massavoimien resultantti on

$$
\mathbf{F}=\int_{V} \rho \mathbf{b d} V .
$$

Tilavuusalkioon $\mathrm{d} V_{0}$ liittyvä massan arvo $\mathrm{d} m$ on massan säilymisen periaatteen nojalla sama kuin edellä eli $\mathrm{d} m=\rho \mathrm{d} V=\rho_{0} \mathrm{~d} V_{0}$. Tässä $\rho_{0}$ on tiheys kyseisessä pisteessä alkutilassa. Täten tilavuusalkioon $\mathrm{d} V$ vaikuttava massavoima voidaan kirjoittaa myös muodossa $\mathrm{d} \mathbf{F}=\rho_{0} \mathbf{b d} V_{0}$ ja täten kappaleeseen vaikuttavien massavoimien resultantti on

$$
\mathbf{F}=\int_{V_{0}} \rho_{0} \mathbf{b d} V_{0}
$$

Tämä on haettu muoto, koska kyseessä on integraali alkutilan tilavuuden yli.

Jos rajoitutaan statiikkaan, liikemäärän taseen periaate sanoo, että kappaleeseen (sen nykytilassa) vaikuttavien ulkoisten voimien resultantti on nolla eli saadaan kaavojen (5) ja (8) perusteella kappaleen alkutilan geometriaan liittyvä yhtälö

$$
\int_{S_{0}} \mathbf{T} \mathrm{d} S_{0}+\int_{V_{0}} \rho_{0} \mathbf{b d} V_{0}=\mathbf{0} .
$$

Yhtälön kehittely eteenpäin mm. vastaavan paikallisen differentiaaliyhtälön johtamiseksi vaatii pseudotraktiota $\mathbf{T}$ koskevia lisäkaavoja, joihin ei puututa tässä. 
Edellä kuviin 2 ja 3 liittyen on oleellista, että mitään voimia tai jännityksiä ei ole piirretty näkyviin vaikuttamaan alkutilan geometriassa. Esimerkiksi lähteessä [3] alkutilaan on liitetty monasti kuvissa voimasuureita ilmeisenä tarkoituksena saada lisää havainnollisuutta esitykseen. Tällainen käsittelytapa on kuitenkin erittäin harhaanjohtava ja sitä tulisi välttää eli vielä: fysiikka tapahtuu vain nykytilassa ja vain siellä voi esiintyä voimasuureita.

Artikkelin lopussa on esitetty kaksi yksinkertaista esimerkkitapausta, joissa pyritään havainnollistamaan erityisesti eräitä suureisiin b ja $\mathbf{T}$ liittyviä piirteitä.

\section{Jännityskomponenteista}

Cauchyn jännityksen tavanomaisten jännityskomponenttien kuten $\sigma_{x}, \tau_{x y}$, jne. fysikaalinen merkitys selostetaan yleensä alan oppikirjoissa myös kuvia apuna käyttäen melko perusteellisesti. Kun sitten tullaan suurten siirtymien yhteydessä tarvittaviin mutkikkaampiin suureisiin kuten toisen Piolan-Kirchhoffin jännitystensorin komponentteihin, rajoittuu esitys usein vain kompakteihin tensorikaavoihin ilman vaivaantumista kuvallisiin selostuksiin. Kyseinen lähestymistapa ei voi olla opetuksellisesti oikea. Lähde [4] muodostaa tähän liittyen ansiokkaan positiivisen poikkeuksen.

\section{Esimerkki 1}

Kuva 4 esittää aineominaisuuksiltaan ja muodoltaan $Y$-akselin suhteen pyörähdyssymmetrisen kappaleen poikkileikkausta. Kappale pyörii $Y$-akselin ympäri vakioarvoisella kulmavauhdilla $\omega$. Kappaleeseen vaikuttaa lisäksi vakioarvoinen painovoimakenttä, jonka intensiteetti on $g \mathbf{j}$. Tarkastellaan tähän tapaukseen liittyvää massavoiman intensiteettiä $\mathbf{b}$.

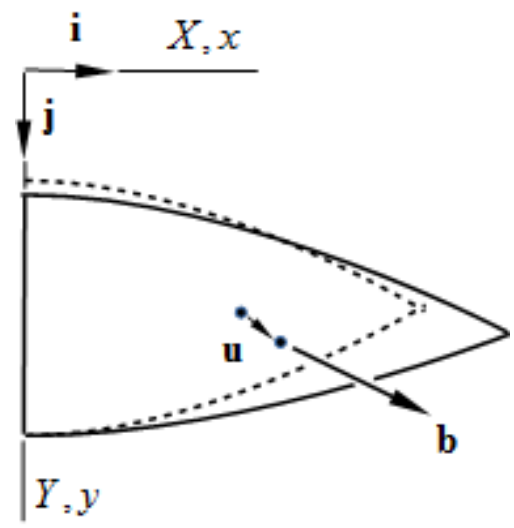

Kuva 4. Pyörähdyssymmetrisen kappaleen poikkileikkaus ja eräitä merkintöjä.

Kyseessä on staattinen tapaus $X, Y, Z$-koordinaatiston suhteen, kun tämä koordinaatisto asetetaan pyörimään kappaleen mukana. Koordinaatiston liikkeen (ei 
inertiaalikoordinaatisto) johdosta tarkasteluun tulee ottaa mukaan näennäisvoimakenttä, jonka intensiteetti on tunnetusti $\omega^{2} e \mathbf{i}$, jossa $e$ on tarkasteltavan pisteen etäisyys pyörimisakselista. (Tässä käsitellään tilannetta $X, Y$-tasossa.)

Ensinnäkin voidaan todeta yleisesti, että alkudatana täytyy tietenkin otaksua riippuvuus $\rho_{0}=\rho_{0}(X, Y, Z)$ annetuksi eräänä tietona kappaleen alkutilan aineominaisuuksista. Sen sijaan vastaava riippuvuus $\rho=\rho(X, Y, Z)$ nykytilaan liittyen on suurten siirtymien teoriassa aluksi tuntematon. Massan säilymisen periaate antaa nimittäin yhteyden $\rho=\rho_{0} / J$, jossa $J$ on kuvaukseen (1) liittyvä Jacobin funktionaalideterminantti. Sen arvo taas riippuu siirtymistä, jotka ovat aluksi tuntemattomia. Todettakoon kuitenkin, että lausekkeessa (8) ei tarvitse tuntea nykytilan tiheyttä $\rho$.

Pienten siirtymien teoriassa jätetään siirtymien vaikutus suureen $\omega^{2} e \mathbf{i}$ arvoon huomiotta ja asetetaan nykytilan yleisen ainepisteen suhteen approksimaatio $x \approx X$ ja siis tässä $e=x \approx X$. Siirtymillä ei ole tietenkään mitään vaikutusta suureeseen $g \mathbf{j}$.Täten saadaan intensiteetti

$$
\mathbf{b}=\omega^{2} X \mathbf{i}+g \mathbf{j} .
$$

Tämä yhteys on periaatteessa muotoa $\mathbf{b}=\mathbf{b}(X, Y, Z)$ ja kelpaisi sellaisenaan käytettäväksi lausekkeessa (8) integrointia suoritettaessa.

Suurten siirtymien teoriassa $x=X+u$ ja siis $e=x=X+u$ ja saadaan intensiteetti

$$
\mathbf{b}=\omega^{2}(X+u) \mathbf{i}+g \mathbf{j} .
$$

Tämä ei kelpaa sellaisenaan vielä käytettäväksi lausekkeessa (8), koska tarvittaisiin lisäksi tieto siirtymäkomponentista $u$ periaatteessa muodossa $u=u(X, Y, Z)$, joka yhteys on aluksi tuntematon ja saadaan vasta osana kokonaisratkaisua. Kaava (11) on suurten siirtymien teoriaan liittyvä yksinkertainen ilmentymä siitä, että b ei ole välttämättä etukäteen annettu suure kuten pienten siirtymien teoriassa on totuttu ajattelemaan. Tulos lisää ymmärrettävästi tarvetta käyttää iteratiivisia ratkaisumenetelmiä.

\section{Esimerkki 2}

Kuva 5 esittää kuvan 2 tyyppistä tapausta varustettuna joillakin lisämerkinnöillä. Kappaleen ulkopuolelle otaksutaan paikan suhteen vakioarvoinen (paineen arvo $p$ ) hydrostaattinen painekenttä, joka on aiheuttanut kappaleen siirtymän $\mathbf{u}=\mathbf{u}(X, Y, Z)$ alkutilan suhteen. Tarkastellaan kappaleen pintaan vaikuttavia traktioita. 


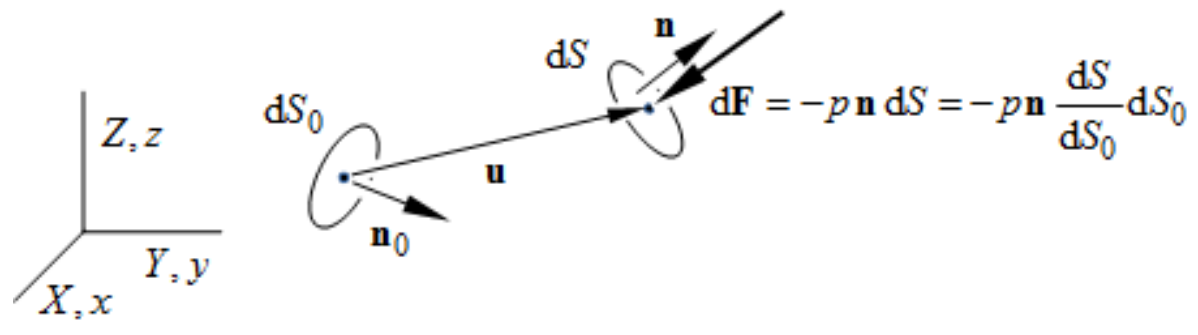

Kuva 5. Pinta-alkioon d $S$ painekuormituksen johdosta vaikuttava voima-alkio dF .

Alkutilan pinta-alkioon $\mathrm{d} S_{0}$ liittyvä ulospäin suunnattu yksikkönormaalivektori olkoon $\mathbf{n}_{0}$ ja vastaava suure nykytilan pinta-alkioon $\mathrm{d} S$ liittyen $\mathbf{n}$. Näiden välillä on melko mutkikas riippuvuus, joka kulkee nimellä Nansonin kaava, esimerkiksi [1, s. 169]. Oleellista on kuitenkin, että vektorin n suuntautuneisuus nykytilassa riippuu siirtymistä kuten on ilmeistä jo pelkästään kuvaa 5 katsomalla. Kun traktio on tässä paineen johdosta

$$
\mathbf{t}=-p \mathbf{n}
$$

se ei siis ole annettu suure, koska se riippuu vielä yhteyksistä (2). Sama koskee myös pseudotraktiota $\mathbf{T}=-p \mathbf{n}\left(\mathrm{d} S / \mathrm{d} S_{0}\right)$, joka on kaavan (6) mukaisesti vektorin $\mathbf{t}$ suuntainen.

Pienten siirtymien teoriassa on totuttu reunaehtojen suhteen tavanomaiseen reunan jakoon osiin $S_{\mathrm{u}}^{0}$ ja $S_{\mathrm{t}}^{0}$, jotka ovat vastaavasti ns. siirtymäreuna ja traktioreuna. Edellisessä reunaehto esitetään muodossa $\mathbf{u}=\overline{\mathbf{u}}$ ja jälkimmäisessä muodossa $\mathbf{t}=\overline{\mathbf{t}}$, jossa $\overline{\mathbf{u}}$ ja $\overline{\mathbf{t}}$ ovat annetuiksi otaksuttuja paikan funktioita. Tarkastellaan nyt esimerkkinä kuvan 5 tapausta ja otaksutaan, että alkio $\mathrm{d} S_{0}$ kuuluu alueeseen $S_{\mathrm{t}}^{0}$ ja palataan pienten siirtymien teoriaan. Silloin toimitaan alkutilan geometrian mukaan ja traktio on siis annettu (koska $\mathbf{n}_{0}$ tiedetään alkutilan annetun geometrian perusteella) ja traktioreunaehtoon voidaan asettaa annettu arvo $\overline{\mathbf{t}}=-p \mathbf{n}_{0}$.

Suurten siirtymien teoriassa voidaan myös suorittaa reunan jako osiin $S_{\mathrm{u}}^{0}$ ja $S_{\mathrm{t}}^{0}$. Jälkimmäiseen tapaukseen liittyen voitaisiin siis ajatella asetetuksi vastaavasti preudotraktiota koskeva reunaehto $\mathbf{T}=\overline{\mathbf{T}}$. Äskeinen tarkastelu osoitti kuitenkin, että aluksi tässä ei ole käytettävissä annettua pseudotraktion arvoa, koska se riippuu mm. vielä tuntemattomista siirtymistä. Suurten siirtymien teorian epälineaarisuus ja tarve iteratiivisiin ratkaisumenetelmiin tulee jälleen esille.

\section{Loppuhuomautuksia}

Riippuu tietenkin suurten siirtymien teorian opetuksen käyttöön osoitetusta ajasta ja tarkoitusperistä, onko syytä siirtyä tässä artikkelissa sovelletuista yksinkertaisista merkintätavoista indeksiesitykseen ja Einsteinin summausääntöön sekä mahdolliseen indeksivapaaseen tensoriesitykseen. Näitä mainittuja jälkimmäisiä työkaluja käyttäen 
käsittely tietenkin lyhenee oleellisesti. Tiivistäminen ei saa kuitenkaan tapahtua ilman havainnollisuuden mukanaoloa.

\section{Kiitokset}

Kiitän professori Juha Paavolaa ja tekniikan tohtori Kari Santaojaa artikkelin aiheisiin liittyvistä keskusteluista sekä heidän artikkelin käsikirjoitukseen esittämistään kommenteista.

\section{Viitteet}

[1] L. E. Malvern, Introduction to the Mechanics of a Continuous Medium, PrenticeHall, 1969.

[2] A. J. M. Spencer, Continuum Mechanics, Dover,1980.

[3] Y. C. Fung, Foundations of Solid Mechanics, Prentice-Hall, 1965.

[4] K. Washizu, Variational Methods in Elasticity and Plasticity, 3rd ed., Pergamon Press, 1982.

Eero-Matti Salonen

Sibeliuksenkatu 3 B 25, 00250 Helsinki

eeromatti.salonen@gmail.com 